\title{
Holistic Approach for Management of Obsessive Compulsive Disorder
}

DEEPAK SINGH, PRANAV PANDYA and PRAGYA S. LODHI

\begin{abstract}
Obsessive Compulsive Disorder is one of the least understood, least diagnosed, most disabling of the anxiety disorders. The aim of present study was to evaluate the effectiveness of holistic approach on Obsessive Compulsive Disorder patients. Holistic approach is an integration of Psychology, Ayurveda and Yogic techniques. Sixty participants with a diagnosis of Obsessive Compulsive Disorder were selected though quota sampling. Participants were received 45 individual sessions of therapeutic interventions of holistic approach. Severity of disorder was measured before and after intervention. The obtained data were statistically analyzed through paired t-test. Results: There where a significant reduction in obsession as well as in compulsion of participants. Conclusion: Holistic Approach is effective intervention and positively associated with durable improvement in obsession and compulsion of participants.
\end{abstract}

Keywords: Holistic Approach, Obsessive Compulsive Disorder, Free-Association, Yoga-Nindra, Pranayama, Baccopa Moneri, Acorus calamus and Nardostachys jatamansi.

The nature of the psychological disorder is very complex, and it is very difficult to understand and diagnose psychological disorder until it manifests itself in behavior. Some people have the recurrent, intrusive and persistent thoughts (or images or impulses) that cause marked anxiety or distress; or they are engaged in repetitive behavior or mental act to prevent or reducing distress, not to provide pleasure or gratification. Due to poor insight about the disorder, generally they blame themselves and believe that it is a kind of bad habit. But truly, it is a complex psychological disorder known as Obsessive Compulsive Disorder (OCD). Most of them have found that a deficit of inhibition and alteration of cognitive flexibility could explain inflexibility and repetitive thoughts and actions typical of all types of Obsessive Compulsive disorders (Dupuy, Rouillon \& Bungener, 2012).

Obsessive Compulsive Disorder is a common and often chronic and disabling disorder (American Psychiatric Association, 2000). Obsessive Compulsive Disorder is one of the psychological problems which are rarely diagnosed because of the poor insight about the disease and also due to strong social stigma attached with mental problem. Rapport (1990) states "Obsessive Compulsive Disorder remains one of the least understood, least diagnosed, and most disabling of the anxiety disorders." In a 2001 World Health Organization mental health report, it was estimated that, in the year 2000, OCD was among the top 20 causes of illness-related disability, worldwide, for individuals between 15 and 44 years of age. Moreover, many other research reports cite OCD as the fourth most common mental illness after phobias, substance abuse, and major depression. Findings demonstrated the significant impact of climate change on the nature of the concerns experienced by people with OCD checking subtype (Jones et al., 2012). The worldwide prevalence of Obsessive-Compulsive Disorder is approximately $2 \%$ of the general population. Avoidance is common in $\mathrm{OCD}$, and it is particularly frequently associated with contamination obsessions (Starcevic et al., 2011). Social Phobia is an anxiety disorder that frequently co-occurs with obsessive- 
compulsive disorder (Assuncao et al., 2012). The most common complication of Obsessive Compulsive Disorder is depression (Sasson et al., 1997). It is a lifelong mental illness and recovery from it is gradual and ongoing treatment is necessary to help prevent relapses (Thobaben, 2012).

Today, a number of approaches applicable on this field both in physiological and psychological way, but no one is certain about the root cause of disorder because many factors play a significant role on a person individually or collectively, and for this reason different approaches explain the causes differently. As far as the management approaches are concerned, currently, there are two widely utilized treatment approaches: pharmacological management and behavioral modification in the form of exposure and response prevention.

A major disadvantage of drug treatment for Obsessive Compulsive Disorder, as for other anxiety disorder, is that the relapse rate is very high following discontinuation of the drug. In the market numbers of medicines are available but they cause many side effects and relapse rate is very high approximately $90 \%$ upon discontinuation the medicine (Dolberg et al., 1996). The effectiveness of individual therapy by exposure and response prevention (ERP) for obsessivecompulsive disorder is well established, yet not all patients respond well, and some show relapse on discontinuation (Abramowitz, 2012). Behavioral approach is of limited help to those who have obsessions but not compulsions (Hohagen et al., 1998). After all, the treatment affects obsessions by blocking closely linked compulsive acts. Finally, the favorable results come mainly from studies of cleaning and checking compulsions. The effectiveness of this approach with other kinds of compulsions is unclear (Ball, Baer \& Otto, 1996).

The available therapies do provide satisfactory treatment of this disorder because they have their own limitations. Still the prognosis of Obsessive
Compulsive Disorder is poor. Marks (1981), suggest a need to investigate additional treatment modalities. In order to remove this rate limitation a new holistic approach was developed with aim of providing a maximum relief to the patients in short period of interventions. In holistic approach a general label is applied to any method that focuses on the whole living organism. Holistic approach is an umbrella term for a number of different interventions such as Free-association, Yoga-nidra, Pranayama, Gayatri Mantra Jap and Herbal medicines. Philosophical and Spiritual foundation of treatment and care promises not only to deepen the insights and skills of clinicians but also to empower clients as participants in their own journeys toward wellness and beyond (Olson, 2012). There is some evidence of effectiveness of these interventions from small studies and literatures; however, no large study has investigated the effects. In addition, studies have been limited to people who fulfilled narrow entry criteria in terms of their difficulties and types of interventions. It is, therefore, not yet possible to identify this form of holistic approach will have an impact on those with a spectrum of cognitive and behavioral difficulties. The key effectiveness questions for holistic approach concern its likely success when the recipients have a variety of difficulties as well as a diagnosis of Obsessive compulsive disorder.

\section{METHODS}

\section{Sample, Sampling \& Study design}

We carried out a new intervention to manage the recurrent thoughts and repetitive behavior in people with obsessive compulsive disorder. Sixty participants with a diagnosis of Obsessive Compulsive Disorder were selected through Quota Sampling from private clinics, in which thirty are male and thirty are female participants. Participants were received 45 individual sessions of therapeutic interventions of holistic approach. 'Single Group Design' was used in which severity 
of disorder was measured before and after interventions.

\section{Inclusive and exclusion criteria}

Participants were recruited from private clinics in Haridwar and Hyaderabad districts from March 2006 to October 2009. Participants were included if they had been suffer from obsessive compulsive disorder for at least one year, had a diagnosis of obsessive compulsive disorder based on DSMIVTR (American Psychiatric Association, 2000) and evidence of clinical interview \& Obsessive Compulsive Scale. Only those having Obsessive Compulsive Disorder were included in the study, while those who were not able to fulfill the criteria were excluded from the sample. Exclusion criteria included current medication use and primary psychiatric diagnosis other than Obsessive Compulsive Disorder.

\section{Intervention}

Several programs are available to test, but the researchers have developed a new approach the first of its kind. Holistic approach is an umbrella term for a combination of different interventions which focuses on the whole living organism. The holistic approach is based on the principle of psychology, yoga and ayurveda.

Intervention consisted of 45 face-to-face sessions, each involving a combination of different techniques of Psychology, Ayurveda and Yoga such as Free-association, Yoga-nidra, Pranayamas (Bhramari \& Pranakarshan), Gayatri mantra japa and herbal medicines (Baccopa moneri, Acorus calamus and Nardostachys jatamansi). The therapists were graduate psychologists and medical professionals. Therapy was delivered to individuals on at least three days per week until 45 sessions were completed. Each session was of 60 minutes in which they performed pranayamas for 10 minutes, Gayatri Mantra Jap for 10 minutes, Freeassociation for 20 minute, Yoga-nidra for 20 minute and $300 \mathrm{mg}$ herbal medicines mixture in powder form were given to the patients. The percentages of herbs used are shown in Table (1).

Table (1):

\begin{tabular}{|l|l|c|c|c|}
\hline \multicolumn{5}{|c|}{ Herbal Medicines } \\
\hline Common Name & \multicolumn{1}{|c|}{$\begin{array}{c}\text { Botanical } \\
\text { Name }\end{array}$} & Part Used & $\begin{array}{c}\text { Percent } \\
(\%)\end{array}$ & $\begin{array}{c}\text { Wt. of each herb (in } \\
\text { mg) }\end{array}$ \\
\hline Brahmi & Baccopa moneri & Leaves & $40 \%$ & 120 \\
\hline Jatamansi & $\begin{array}{l}\text { Nardostachys } \\
\text { jatamansi }\end{array}$ & Rhizome & $40 \%$ & 120 \\
\hline Vach & Acorus calamus & Rhizome & $20 \%$ & 60 \\
\hline & & & $100 \%$ & $300 \mathrm{mg}$ \\
\hline
\end{tabular}

\section{Procedure}

A written consent was taken from all the participants prior to the inclusion in the trial. After baseline assessment participants were provided intervention. Intervention continued for 45 individual sessions (approximately 16 weeks). In addition to the assessments on outcome measures, data were also collected on clinical history and severity of obsessions and compulsions. Social behavior data were collected from friends or relative informants who were independent of the trial but not masked to group allocation. 


\section{Statistical analysis}

Severity of Obsession and Compulsion were measured before and after intervention. After the collection, the data was meaningfully analyzed to test the hypothesis. The aim of analysis was to summarize the complete observation in such a manner that a meaningful relationship might be established between independent and dependent variable. After collection and scoring of research data, we converted raw scores into standard scores (t-scores). The obtained data were statistically analyzed through paired t-test.

\section{RESULTS}

Sixty participants were recruited to the trial, in which fifty percentage $(n=30)$ were males and the mean age was 34 years; fifty percentage $(n=30)$ were females and the mean age was 28 years. The results are shown in Table $2,3 \& 4$.

Hypothesis (1): There is positive effect of Holistic Approach on the level of Obsession Compulsive Disorder patients.

Table (2):

\begin{tabular}{|l|l|l|l|l|l|l|l|l|}
\hline S.No. & Group & $\mathbf{N}$ & Mean & SD & $\mathbf{r}$ & SED & t-value & $\begin{array}{c}\text { Level of } \\
\text { Significance }\end{array}$ \\
\hline 1. & Pre-Test & 60 & 61.27 & 5.65 & \multirow{2}{*}{0.52} & 0.63 & 23.75 & $\begin{array}{l}\text { Significant at } \\
0.01 \text { level of } \\
\text { confidence }\end{array}$ \\
\cline { 1 - 8 }
\end{tabular}

The directional hypothesis formulated has been accepted at 0.01 level of confidence. The result table 2 shows pre-test and post-test mean values 61.27 and 46.38 respectively of 60 patients. The correlation is 0.52 . The obtained t-value is 23.75 which is significant at 0.01 level of confidence.
This result shows the positive effect of holistic approach on Obsessive Compulsive Disorder.

Hypothesis (2): There is positive effect of Holistic Psychotherapeutic Approach on the level of Obsession Compulsive Disorder among male patients.

Table (3):

\begin{tabular}{|c|c|c|c|c|c|c|c|c|}
\hline S.No. & Group & $\mathbf{N}$ & Mean & SD & $r$ & SeD & t-value & $\begin{array}{c}\text { Level of } \\
\text { Significance }\end{array}$ \\
\hline 1. & Pre-Test & 30 & 60.23 & 5.06 & \multirow{2}{*}{0.52} & \multirow{2}{*}{0.82} & \multirow{2}{*}{17.5} & \multirow{2}{*}{$\begin{array}{l}\text { Significant at } \\
0.01 \text { level of } \\
\text { confidence }\end{array}$} \\
\hline 2. & Post-Test & 30 & 46.2 & 3.35 & & & & \\
\hline & & & & & & & $\mathrm{df}=29$ & \\
\hline
\end{tabular}


The directional hypothesis formulated has been accepted at 0.01 level of confidence. The result table-3 shows pre-test and post-test mean values 60.23 and 46.2 respectively of 30 male patients. The correlation is 0.52 . The obtained t-value is 17.5 which is significant at 0.01 level of confidence. This result shows the positive effect of
Holistic Psychotherapeutic Approach on Obsessive Compulsive Disorder male patients.

Hypothesis (3): There is positive effect of Holistic Psychotherapeutic Approach on the level of Obsession Compulsive Disorder among female patients

Table (4):

\begin{tabular}{|c|l|l|l|l|l|l|l|l|}
\hline S. No. & Group & N & Mean & SD & $\mathbf{r}$ & SED & t-value & $\begin{array}{c}\text { Level of } \\
\text { Significance }\end{array}$ \\
\hline 1. & Pre-Test & 30 & 62.3 & 6.09 & \multirow{2}{|c|}{0.51} & 0.97 & 16.53 & $\begin{array}{l}\text { Significant at } \\
0.01 \text { level of } \\
\text { confidence }\end{array}$ \\
\hline 2. & Post-Test & 30 & 46.57 & 3.18 & & & $\mathrm{df}=29$ & \\
\hline
\end{tabular}

The directional hypothesis formulated has been accepted at 0.01 level of confidence. The result table-4 shows pre-test and post-test mean values 62.3 and 46.57 respectively of 30 female patients. The correlation is 0.51 . The obtained t-value is 16.53 which is significant at 0.01 level of confidence. This result shows the reduction of the symptoms of Obsessive Compulsive Disorder in female patients after the intervention of Holistic Psychotherapeutic Approach.

\section{DISCUSSION}

This paper reports significant difference between the data of before (pre-test) and after (post-test) intervention. It is evident from the results that holistic approach produced significant reduction in the level of Obsessive Compulsive Disorder. The all three directional hypothesis are accepted at the 0.01 level of significance. This proves the effectiveness of holistic approach in reducing the level of Obsessive Compulsive Disorder among both genders.

Holistic approach is an umbrella term for a combination of different interventions which focuses on the whole living organism. The holistic approach is based on the principle of Psychology, Yoga and Ayurveda, which includes Freeassociation, Yoga-nidra, Pranayamas, Gayatri mantra jap and herbal medicines (Brahmi, Vach \& Jatamansi) .

In the present study researchers have selected three effective herbs which are closely related to psychological disorders because these drugs affect the Central Nervous System. These herbs are Brahmi (Baccopa monneri), Vach (Acorus calamus), and Jatamansi (Nardostachys jatamansi). These medicines are traditionally used as nervine tonic, intellect promotives and tranquilizers. These medicines basically strengthen the nervous system and reduce the symptoms of anxiety. (Kurup, et al., 1979; Sharma, 2001; Worrier, et al., 1996).

The Obsessive Compulsive Disorder is caused by low serotonin activity (Rapport, 1989, 1991; Klerman et. al., 1994; Jenike, 1992). The research finding proved that the administration of Vach (Acorus calomus) increased the serotonin level in the cerebral cortex of the brain of rat (Hazra \& Guda, 2002). It is possible that this medicine may produce the similar effect on brain of human which 
may cause to reduce the symptoms of Obsessions \& Compulsions. Jatamansi plant is useful in psychological problems (Jain \& Tarafder, 1970). Singh and Dhawan (1997) conclude in their research that, Brahmi is very effective medicine for neuropsychological problems. Pandey, Aruna and Dubey (1993) have found that the use of Brahmi significantly improved concentration ability, memory span and over all mental performance of subjects with mild and moderate mental deficiency.

The second component of the holistic approach which may provide significant effect on Obsessive Compulsive Disorder is Gayatri Mantra Japa. In essence, Gayatri Mantra is a universal prayer. It might help the patients to release their suppressed emotions, provided mental supports and feelings of security. The trust over the supreme power may induce the hope for more positive life. In the present study, it might also help patients to alter their obsessive thoughts. Gangdev (1998) in his research concluded that religious faith could have a healing effect and it helps rapid resolution of obsessions.

The Gayatri mantra is the most powerful mantra of purification and transformation known to the yogic traditions. Gayatri matra has both biological and physiological effects. The secret of the super natural impact of Gayatri Mantra in the physical domains of life lies in its unique configuration of the specific syllables- the seeds of Sabda (sound), which is derived from the esoteric depths of the absolute science of Sabda brahmNada Brahm. The cyclic renunciation of this mantra stimulates the subliminal power of energy centers in the subtle body. The masters of MantraVidya know that words are uttered by different parts of the mouth such as, throat (larynx), tongue, teeth, lips and the root of the mouth from which sound emits stretch unto different part of the body and put impact the energy of these glands gets stimulated. Mantra has been composed on this basis. Activation of these energy centers may help to hormonize the physical, mental and emotional domains of organism. Selwamurthi, (1998) in his research 'Physiological Effects of Mantras' concluded that its effects on nervous system and reduces stress. Sharma, (1994) in his research 'Therapeutic Benefit of Gayatri Mantra" has found its effectiveness in psychological disorders.

The third component of holistic approach is Pranayama. In the present study the researchers made the subjects practiced two pranayam as, one is Bhramari pranayama and another is Pranakarshan pranayama. Bhramari pranayam involves breathing as well as sound effect. The sound produced during this process helps to release the conjunction of the cerebrospinal fluid in the brain region which may indirectly reduces anxiety symptoms. Sakthignanavel, (2002) found the positive effect of breathing exercise on the level of Anxiety. Pranakarshan pranayama is an advanced practice of pranayama. It is totally based on strength of determination, positive thinking and emotions. It involves two processes; first is physical practice i.e. the technique of breathing control and second is psychological process i.e. positive auto suggestions. Traditionally, pranayama is used as one of the effective technique for mind. The sincere practice pranayama helps the subject to control over the breath which leads him to control over the mind and its activities. When participants get control over their mind, which lead them to control over their thoughts and behaviors, it may produce significant effect in controlling intrusive thoughts and compulsive behaviors. Khalsa, et al., (1996) found the positive effect of breathing exercise on the level of Obsessive-Compulsive Disorder.

Another component of the study is Yoga-nidra. Yoga-Nidra, is a powerful technique in which one relaxes consciously. It is a systematic method of inducing complete physical, mental and emotional relaxation. Literally, Yoga-Nidra means 'psychic sleep' i.e. sleep with full awareness. In this threshold state between sleep and wakefulness, 
contact with the subconscious and unconscious dimensions occurs spontaneously. In the practice of Yoga-Nidra the body sleeps but the mind remains awake listening to the instructions. In psychology, the state achieved in Yoga-Nidra is turned into hypnotic state, a state between sleep and wakefulness. In Yoga-Nidra, the state of relaxation is reached by turning inwards, away from outer experiences. In the present study to enhance the therapeutic value and effectiveness of Yoga-Nidra, researcher gave specific instructions to the patients according to their conditions. This was the new experiment along with the general practice of Yoga-Nidra. In this relaxing state the mind became calm and more receptive. The positive instructions given by researcher were more effective \& helpful to the patients in managing their obsessions and compulsions easily. Mathew (1981) reported that Yoga-Nidra is a successful therapy for both recent and longstanding psychological disturbance of all kinds, especially high anxiety levels and neurotic behaviour patterns. Bahrke (1979) also concluded on the basis of his study that the practice of yogic relaxation has been found to reduce tension effectively and to improve the psychological wellbeing of sufferers from anxiety. Bhushan \& Sinha (2000) reported that the practice of Yoga-Nidra significantly reduces the anxiety and hostility levels of the practicing subjects. Shealy (1998) concluded that Yoga-Nidra is a successful treatment for insomnia. In this manner, various researches show that the technique of Yoga-Nidra can successfully be administered to manage various psychological disorders.

Last component of this study was freeassociation which is one of the techniques of catharsis developed by Sigmund Freud and used by different psychoanalysts. A psychodynamic technique in which the patient describes any thought, feeling, or image that comes to mind, even if it seems unimportant the assumptions is that this kind of free flowing, uncensored talking will provide clues to unconscious material (Comer, 2002). Freud (1936) says that free association is very effective technique to uncover unconscious events and conflicts. It helps the researcher to understand the patient and also give the relief to the patient because generally they have many conflicts, beliefs and repressed thoughts that creates fear and anxiety. Patients usually do not share these thoughts to anyone. Researcher has found that many patients release their suppressed emotions during free-association sessions. Catharsis is the emotional discharge, which brings relief to emotional tension and a concomitant or consequent change in the individual's state of being. Freudian psychoanalysis, to describe the act of expressing deep emotions often associated with events in the individual's past which have never been adequately expressed. Catharsis is also an emotional release associated with talking about the underlying causes of a problem. Breuer and Freud described catharsis as an involuntary, instinctive body process, for example crying (Breuer \& Freud, 1974). The American Psychological Association (2007) also associates catharsis with the psychodynamic theory and defines it as "the discharge of affects connected to traumatic events that had previously been repressed by bringing these events back into consciousness and reexperiencing them". There are two essential components of catharsis: the emotional aspect (strong emotional expression and processing) and the cognitive aspect of catharsis (insight, new realization, and the unconscious becoming conscious) and as a result - positive change. At the heart of most of the therapeutic systems, is a belief that the emotional discharge of repressed traumatic material brings relief to emotional tension, thereby resulting in an alleviation of physical and psychological symptoms of patient.

\section{Conclusion}

The combinations of these specific techniques have collective effect on the patients that cause to 
significant reduction in the level of Obsessive Compulsive Disorder. Thus, through this study has been highlighted that the holistic approach can provide a new strategy for management of Obsessive Compulsive Disorder. The findings of present research are an important exploration with wide scope for further research and applications.

DEEPAK SINGH, PhD, Assistant Professor, Department of Psychology, PRANAV PANDYA, MD, Chancellor, Dev Sanskriti Vishwavidyalaya; PRAGYA S. LODHI, PhD, Assistant Professor, Department of Psychology, Dev Sanskriti Vishwavidyalaya, Haridwar, India.

\section{REFERENCES}

Abramowitz, J. S., Baucom, D. H., Wheaton, S. B., Fabricant, L. E., Paprocki, C. \& Fischer, M. S. (2012) Enhancing Exposure and Response Prevention for Obsessive-Compulsive Disorder: A Couple-Based Approach. Behavior Modification, 36(6), 34-39.

American Psychiatry Association (2000) Diagnostic and statistical manual of mental disorders $\left(4^{\text {th }}\right.$ ed., text revision). Washington, DC: Author.

American Psychological Association (2007) Dictionary of Psychology. Washington, DC: Author.

Assunção M. C., Lucas, C. C. D., Mathis, M. A., Gedanke, S. R., Arzeno, F. Y., Rosário, M. C., Constantino, M. E. \& Rodrigues, T. A. (2012) Social phobia in obsessive-compulsive disorder: Prevalence and correlates. Journal of Affective Disorders. 2012 Aug 1. [Epub ahead of print].

http://www.ncbi.nlm.nih.gov/pubmed/22858214/ Retrieved on 29 October 2012.

Bahrke, M. S. (1979) Exercise, Meditation and Anxiety reduction: a review. American Corr. Therapy Journal, 33, 41-44.

Ball, S. G., Baer, L. \& Otto, M. N. (1996) Symptom subtypes of Obsessive Compulsive Disorder in behavioural treatment studies: A quantitative review. Behavior Research and Therapy. 34, 47-51.

Bhusan, S. \& Sinha, P. (2000) Yoga nidra and Management of Anxiety and Hostility. Journal of Indian Psychology, 49, 56-62.
Breuer, J. \& Freud, S. (1974) Studies on hysteria. New York, NY: Harmondsworth, Penguin Books.

Comer, J. R. (2002) Fundamentals of Abnormal Psychology, (IIIrd edit.). New York, NY: Worth Publishers.

Dolberg, O. T., Lancer, I., Sasson, Y. \& Zohar, J. (1996a) The pathogenesis and treatment of obsessivecompulsive disorder. Clincal Neuropharmacology 19(2), 129-147.

Dolberg, O. T., Sasson, Y., Marazziti, D., Kotler, M., Kindler, S. \& Zohar, J. (1996b) New compounds for the treatment of Obsessive Compulsive Disorder. In H.G.Westernberg, J. A. Den Boer, \& D. L. Murphy (Eds.). Advances in the neurobiology of anxiety disorders. Chicher, England, EL: Wiley.

Dupuy M, Rouillon F, Bungener C. (2012) The role of inhibition in Obsessive-compulsive disorders. Encephale. 2012 Sep 23. pii: S0013-7006(12)00110-8. doi: 10.1016/j. encep. 2012. 06.016. [Epub ahead of print]. http://www.ncbi.nlm.nih.gov/pubmed/23095598/ Retrieval on 29 October 2012.

Freud, S. (1936) The problem of anxiety. New York, NY: Norton.

Gangdev, D. S. (1998) Faith assisted cognitive therapy in obsessive-compulsive disorder. Journal of Psychiatry, 32(4), 575-578.

Hazra, R. \& Guha, D. (2002) Effect of chronic administration of Acorus calomus an electrical and regional monoamine level in rat brain. Biogenic Amines, 17(3), 161-169. http://www.ocdeducationstation.org/ocdfacts/incidence-of-ocd/ Retrieved on 29 October 2012

Jain S.K. and Tarafder C.R. (1970) Medicinal plant-lore of the Santals. (A revival of P.O.Bodding's work). Economic Botany, 24,241-278.

Jenike, M. A. (1992) New developments in treatment of obsessive compulsive disorder. In A. Tasman \& M.B. Riba (Eds.), Review of psychology (Vol.11).

Washington, DC: American Psychiatric Press.

Jones, M. K., Wootton, B. M., Vaccoro, L. D. \& Menzies, R. G. (2012) The impact of climate change on obsessive compulsive checking concerns. Australian \& New Zealand Journal of Psychiatry, 46, 183-184.

Khalsa, D. S. S. \& Beckett, L. R. (1996) Clinical case report: efficacy of yogic techniques in the treatment of Obsessive Compulsive Disorder. International Journal of Neuroscience, 85, 1-17. 
Klerman, G. L., Weissman, M. M., Markowitz, J., Glide, I., Wilner, P. J., Mason, B. \& Sher, M. K. (1994) Medication and Psychotherapy. In A. E. Bergin \& S. L. Garfiel (Eds.), Handbook of Psychotherapy and behavior change $\left(4^{\text {th }}\right.$ ed.). New York, NY: Wiley.

Kurup, D. N. V., Ramadas, V. N. K. \& Josh, S. P. (1979) Hand Book of Medicinal Plants. New Delhi, ND: CCRAS.

Mathew, R. J. (1981) Anxiety and platelet MAO levels after relaxation training. American Journal of Psychiatry, 138(3), 371-373.

Olson, T. (2012) Buddhism, Behavior Change, and OCD. Journal of Holistic Nursing, 30 (3), 86-89.

Pandey, A., Aruna, S. \& Dubey, M. N. (1993) Management of mental deficiency by an indigenous drug Brahmi (Bacopa mennieri). Pharmacologia, 6(1), $1-5$.

Rapoport, J. L. (1989) The biology of obsession \& compulsions. Scientific American. 260, 82-89.

Rapoport, J. L. (1990) The working nightmare: An overview of Obsessive Compulsive Disorder. Journal of Clinical Psychiatry, 5(2), 25-28.

Rapoport, J. L. (1991) Recent advances in obsessivecompulsive disorder. Neuropsychopharmacology, 5(1), $1-10$.

Sakthignanavel, D. A., Tin, A. \& Vanithianathan, K. (2002) Effect Continuous running Yogic Pranayama and combination of continuous running and Yogic

Pranayama on State Anxiety. Journal of Social Science and Humanities, 67, 45-53.

Salkovskis, P. M. (1985) Obsessional-compulsive problems: A Cognitive-behavioural analysis. Behavior Research and Therapy, 23, 571-584.

Salkovskis, P. M. (1989) Cognitive-behavior factors and the persistence of intrusive thoughts in Obsessional problems. Behavior Research and Therapy, 27, 677682.
Salkovskis, P. M. (1999) Understanding and treating obsessive-compulsive disorder. Behavior Research and Therapy, 37(1), 529-552.

Sasson, Y., Zohar, J., Chopra, M., Lustig, M., Iancu, I. \& Hendler, T. (1997) Epidemiology of ObsessiveCompulsive disorder: a world view. The Journal of Clinical Psychiatry, 58(12), 7-10.

Selwamurthi, S. (1998) Physiological effect of Mantra. In Pandya, P. (1998). Akhanada Jyoti, monthly magazine. Mathura: Akhand Jyoti Sansthan.

Sharma, P.V. (2001) Dravyagun Vijyan (vol. II). Varanasi: Chaukhambha Bharati Academy.

Sharma, R. A. (1994) Therapeutic Benefit of Gayatri Mantra. Psychopharmacology, 169(6), 362-9.

Shealy, R. C. (1998) The effectiveness of various treatment techniques in different degrees and distributions of sleep-onset insomnia. In S. Swami (Ed.).Yoga nidra $\left(6^{\text {th }}\right.$ edition). Munger, MG: Bihar School of Yoga.

\section{Singh, H. K. \& Dhawan, B. N. (1997)}

Neuropsycholpharmacological effect of the Ayurvedic footropes Bacopa monnieri Linn (Brahmi). Indian Journal of Pharmacology, 29(5), 359-65.

Starcevic, V., Berle, D., Brakoulias, V., Sammut, P., Moses, K., Milicevic, D. \& Hannan, A. (2011) The natural and correlates of Avoidance in Obessivecompulsive Disorder. Australian \& New Nealand Journal of Psychiatry, 45, 801-802.

Thobaben, M. (2012) Obsessive-Compulsive Disorder (OCD) Symptoms and Interventions. Home Health Care Management \& Practice. 24( 4), 211-213.

Worrier, P. K., Nambiar, M. P. K. \& Ramankutty, C. (1996) Indian Medicinal Plants: a compendium of 500 species (Vol. I-V). Madras, MD: Orient Longman. 